\title{
Routine administration of Anti-D: the ethical case for offering pregnant women fetal $R H D$ genotyping and a review of policy and practice
}

\author{
Julie Kent ${ }^{*}$, Anne-Maree Farrell ${ }^{2}$ and Peter Soothill ${ }^{3}$
}

\begin{abstract}
Background: Since its introduction in the 1960s Anti-D immunoglobulin (Anti-D Ig) has been highly successful in reducing the incidence of haemolytic disease of the fetus and newborn (HDFN) and achieving improvements to maternal and fetal health. It has protected women from other invasive interventions during pregnancy and prevented deaths and damage amongst newborns and is a technology which has been adopted worldwide. Currently about one third of pregnant women with the blood group Rhesus D (RhD) negative in the UK (approximately 40,000 women per year in England and Wales), receive antenatal Anti-D Ig in pregnancy when they do not require it because they are carrying a RhD negative fetus. Since 1997, a test using cell free fetal DNA (cffDNA) in maternal blood has been developed to identify the genotype of the fetus and can be used to predict the fetal RhD blood group.

Discussion: This paper considers whether it is ethically acceptable to continue administering antenatal Anti-D Ig to all RhD negative women when fetal RHD genotyping using maternal blood could identify those women who do not need this product.

Summary: The antenatal administration of Anti-D Ig to a third of RhD negative pregnant women who carry a RhD negative fetus and therefore do not need it raises important ethical issues. If fetal RHD genotyping using maternal blood was offered to all RhD negative pregnant women it would assist them to make an informed choice about whether or not to have antenatal Anti-D Ig.
\end{abstract}

Keywords: Anti-D immunoglobulin, Fetal RHD genotyping, RhD blood group, Ethics, Informed consent

\section{Background}

Currently about one third of pregnant women who are blood group RhD negative in the United Kingdom (UK) (approximately 40,000 women per year in England and Wales [1]), receive antenatal Anti-D immunoglobulin (Anti-D Ig) in pregnancy when they do not require it because they are carrying a $\mathrm{RhD}$ negative fetus [2]. The purpose of administering Anti-D Ig is to reduce the chance of sensitisation to RhD positive blood and so the potential risks of haemolytic disease of the fetus and newborn (HDFN). Since it is now possible to test maternal blood to predict the $\mathrm{RhD}$ blood group of the fetus, our concern is to ask whether it is ethically justifiable for this group of women to continue to be offered Anti-D Ig? Further, while

\footnotetext{
*Correspondence: Julie.Kent@uwe.ac.uk

'Department of Health \& Social Sciences, University of the West of England, Coldharbour Lane, Bristol BS16 1QY, UK

Full list of author information is available at the end of the article
}

the potential risks of HDFN are well established, and the risks of receiving Anti-D Ig are very low, should we accept that pregnant women and their RhD negative fetuses are exposed to a plasma product sourced from non-local, overseas donors where there are no clinical or other benefits to the woman or the fetus?

\section{Discussion}

\section{Administration of Anti-D lg}

Since its introduction in the 1960s Anti-D Ig has been highly successful in reducing the incidence of HDFN and achieving improvements to maternal and fetal health. It has protected women from other invasive interventions during pregnancy and prevented deaths and damage amongst newborns and is a technology which has been adopted worldwide. Yet there are international and local variations in the pattern of its administration [3]. In accordance with current UK NICE guidelines, [4] 
it is recommended that all $\mathrm{RhD}$ negative women in the UK are routinely offered Anti-D Ig prophylactically (ie routine antenatal anti-D prophylaxis - RAADP) during antenatal care (at 28 weeks), and following any antenatal 'potential sensitising event' (PSE) where fetal maternal haemorrhage (FMH) may have occurred (including pregnancy termination). Anti-D Ig is also offered after the delivery but only when a cord blood test shows that the baby is $\mathrm{RhD}$ positive. The above policies are designed to prevent sensitisation in $\mathrm{RhD}$ negative women who carry a $\mathrm{RhD}$ positive fetus and so antibody production arising to HDFN in subsequent pregnancies with RhD positive fetuses. The success of the above programme has led to the incidence of HDFN now being relatively uncommon, although some concern has been expressed about recent cases [5]. If the fetus is $\mathrm{RhD}$ negative then in that pregnancy sensitisation and associated HDFN due to anti-D cannot occur [6].

\section{Non invasive prenatal testing of fetal genotype}

Since 1997, [7] a test using cell free fetal DNA (cffDNA) in maternal blood has been developed to identify the genotype of the fetus and can be used to predict the fetal RhD blood group. This was initially used in women who had already been sensitised and so were at risk of HDFN $[8,9]$, however, from 2008 modifications were made to allow a scaled-up high throughput approach [10]. Standardisation of the test has been the focus of international research, and it has been shown to be very accurate but the small possibility of false negative results remains. If the test gave a false negative result and routine cord blood phenotype testing at birth subsequently identified the fetus as RhD positive then postnatal Anti-D Ig would still be administered at that time, but potentially sensitisation could occur in these women affecting subsequent pregnancies. The risks of this happening have been estimated to be $1: 86,000$ [2]. In the UK, non-invasive (or invasive) fetal blood group genotyping is currently only performed when women's samples are referred to the NHS Blood and Transplant (NHSBT) or Scottish National Blood Transfusion Service (SNBTS) [11] for testing to determine the risk to the fetus when a mother is known to have immune antibodies against the relevant blood group antigen. A multicentre "research for patient benefit" NIHR project has finished recruiting and is awaiting publication. In addition a service implementation pilot that offers a fetal genotyping test to all $\mathrm{RhD}$ negative women is now underway in Bristol and Weston and results are expected in late 2014 [12]. Only the Netherlands and Denmark currently offer this test to all $\mathrm{RhD}$ negative women in order to identify those carrying a fetus that is $\mathrm{RhD}$ negative and to reduce the unnecessary administration of Anti-D Ig $[13,14]$. In Denmark, the decision was made concurrently with the implementation of RAADP and it was recognised that the accuracy of fetal $R H D$ genotyping was similar to that of the cord blood RhD phenotyping used for the administration of postnatal Anti-D Ig. In the Netherlands, RAADP had already been established when fetal $R H D$ genotyping began to be offered to all $\mathrm{RhD}$ negative women in 2011.

\section{The production of Anti-D Ig}

In the UK, polyclonal Anti-D Ig is a blood product manufactured from pooled plasma, predominantly collected from $\mathrm{RhD}$ negative male plasma donors in the United States. These male donors are injected with RhD positive red blood cells to stimulate sensitisation and antibody production. The antibodies can then be harvested following plasmapheresis. A premium is paid to these men in acknowledgement of the potential risks they face as a result of injecting donor red blood cells prior to the donation session. The processing and fractionation of plasma operates to industry standards and must comply with medicinal product regulation in order to minimise the risks of infection or viral transmission or contamination [15].

In the 1970s and 1990s, there were a number of contamination episodes involving Anti-D Ig product in countries such as Ireland and Germany [16,17]. More recently, the UK Royal College of Obstetricians and Gynaecologists noted that: "There is no evidence to suggest that RAADP is associated with adverse events that are of consequence for the mother or baby, other than the possibility of bloodborne infection (author's emphasis), and procedures are in place to minimise these risks" and to inactivate viruses [18]. What is particularly troubling is that the risks of prion transmission and newly emerging viruses are unknown and therefore remain a potential risk for women who continue to receive the product. In addition, administration of Anti-D Ig and adverse incidents relating to its use are a matter of concern for organisations such as Serious Hazards of Transfusion, [19] and concerns have recently been raised about adverse incidents involving the inappropriate and unnecessary administration of Anti-D Ig to women who are RhD positive.

\section{Ethical issues}

Anti-D therapy has no direct benefit to the woman but is designed to promote fetal health in future pregnancies. The ethical (and legal) basis for current policy and practice is that women should be given appropriate information about Anti-D Ig so that they are in a position to give consent to the treatment. But on what basis are women able to make such a decision when the $\mathrm{RhD}$ blood group of their fetus remains unknown? Introduction of fetal $R H D$ genotyping to prevent unnecessary administration of Anti-D Ig would be more consistent with existing policy which is aimed at reducing wasteful use of blood and blood products and ensuring that the right product is 
given to the right person [20]. Moreover, while a recently published cost analysis of mass fetal $R H D$ genotyping suggested that the costs of introducing such a service would not be met by the reduction in use of prophylactic antenatal Anti-D Ig, [21] others have argue that automated testing lowers assay costs below the price of Anti-D Ig and is cost-effective [22]. There are inconsistencies in the application of cost-analysis decision making within the NHS. The highly precautionary approach now taken to managing risks in a post-HIV blood contamination era has meant that a range of values - ethical, social and political - have influenced policy-making in relation to blood safety, rather than relying predominantly on traditional cost-benefit analysis in relation to healthcare interventions [23]. So what values should underpin the policy that about 40,000 women per year in England and Wales continue to receive a blood product they do not need?

We want to suggest that in addition to the audit of Anti-D Ig use in England that is being undertaken by the Royal College of Physicians and NHSBT as part of their joint National Comparative Audit (NCA) program, a review of the ethical issues involved is also needed [24]. Does the well accepted ethical principle that clinicians should do no harm encompass the view that women should not be given a blood product that does them no good? Does consent to the administration of Anti-D Ig also mean that women should first be offered fetal $R H D$ genotyping to establish their need for this product? Current policy and practice in the UK to routinely administer Anti-D Ig emerged at a time when the technology of fetal $R H D$ genotyping was under-developed but a review of the current approach is now timely given the development of new capabilities to test fetal genotype. The widespread adoption of the technology could ensure that women, both in the UK and in other countries, do not receive a blood product unnecessarily. The ethical issues at stake here include weighing the relatively low risks of false negative results associated with fetal RHD genotyping using cffDNA and the costs of implementing mass testing, against the benefits of ceasing the practice of giving this group of pregnant women a human blood product they do not need.

\section{Summary}

In short we have argued that, on ethical grounds, there is a strong case for reviewing policy and practice relating to the routine administration of prophylactic antenatal Anti-D Ig. By making fetal RHD genotyping more widely available, women would be better informed about whether or not they need this blood product.

\section{Competing interests}

The authors declare that they have no competing interests.

\section{Authors' contributions}

JK contributed to the design of the ESRC study, conducted fieldwork, including interviews, analysed the data and reviewed the literature, developed the idea for the paper and wrote the paper. AMF contributed to the design of the ESRC study, the analysis of the data and literature, commenting on the paper and assisting in its revision. PS provided information about current clinical practice, commented on the paper and assisted in its revision. All authors approved the final version of the paper.

\section{Authors' information}

JK is Professor of Sociology of Health Technology and is researching the plasma industry and the use of blood products in maternity care as part of an ESRC funded project: Risk, safety and consent in blood services in the UK. She is author of Regenerating Bodies: Tissue and Cell Therapies in the $21^{\text {st }}$ Century (London: Routledge; 2012). AMF is Associate Professor of Law, Australian Research Council Future Fellow, and collaborator with JK on the ESRC project (above). She is author of The Politics of Blood, Ethics, Innovation and the Regulation of Risk (Cambridge: Cambridge University Press; 2012). PS is a Consultant and Professor of Maternal and Fetal Medicine and a lead for the service implementation pilot of fetal RHD genotyping at Bristol and Weston. He was a grant holder of the NIHR funded project on Reliable Accurate Prenatal non-Invasive Diagnosis (RAPID) http://www.rapid.nhs.uk and National Institute for Health Research, Research for Patient Benefit Programme Grant (PB-PG-0107-12005).

\section{Acknowledgements}

JK and AMF acknowledge and thank the ESRC for funding the project: on Risk, safety and consent in blood services in the UK [RES-062-23-2751] and Dr Helen Busby (University of Leceister) who was the Principal Investigator on the project. AMF also acknowledges additional funding support by the Wellcome Trust [WT087439MF] and the Australian Research Council [FT130101768]. PS acknowledges and thanks the NIHR who funded the Reliable Accurate Prenatal non-Invasive Diagnosis (RAPID) http://www.rapid. nhs.uk / and the National Institute for Health Research for the Research for Patient Benefit Programme Grant (PB-PG-0107-12005)

\section{Author details}

${ }^{1}$ Department of Health \& Social Sciences, University of the West of England, Coldharbour Lane, Bristol BS16 1QY, UK. Faculty of Law, Monash University, Melbourne, Australia. ${ }^{3}$ Fetal Medicine, St Michaels Hospital, University Hospitals Bristol NHS Trust, Bristol, UK.

Received: 7 October 2013 Accepted: 14 February 2014 Published: 25 February 2014

\section{References}

1. Of 723,913 births in England and Wales 2011, 15\% (108,000) were rhesus negative births: http://www.ons.gov.uk/ons/rel/vsob1/birth-summarytables-england-and-wales/2011-final-/sb-births-and-deaths-in-englandand-wales-2011-final-.html.

2. Finning K, Martin P, Summers J, Massey E, Poole G, Daniels G: Effect of high throughput RHD typing of fetal DNA in maternal plasma on use of anti-RhD immunoglobulin in $\mathrm{RhD}$ negative pregnant women: prospective feasibility study. BMJ 2008, 336:816-818.

3. Harkness $M$, Freer $Y$, Prescott RJ, Warner P: Implementation of NICE recommendation for a policy of routine antenatal anti-D prophylaxis: $a$ survey of UK maternity units. Transfus Med 2008, 18:292-295.

4. National Institute for Health and Clinical Excellence: Routine antenatal anti-D prophylaxis for women who are rhesus D negative. Review of NICE technology appraisal guidance 41; 2008.

5. Bolton-Maggs PHB, Davies T, Poles D, Cohen J: Errors in anti-D immunoglobulin administration: retrospective analysis of 15 years of reports to the UK confidential haemovigilance scheme. Int J Obstet Gynaecol 2013, 120:873-878.

6. See Royal College Obstetricians \& Gynaecologists (RCOG): Green-top Guideline 22 The Use of Anti-D Immunoglobulin for Rhesus D Prophylaxis. "It should be noted that anti-D lg does not protect against the development of other antibodies which can cause haemolytic disease of the newborn"; 2011:4. http://www.rcog.org.uk/womens-health/clinical-guidance/use-anti-dimmunoglobulin-rh-prophylaxis-green-top-22. 
7. Lo YM, Corbetta N, Chamberlain PF, Rai V, Sargent IL, Redman CW: Wainscoat JS: presence of fetal DNA in maternal plasma and serum. Lancet 1997, 350:485-487.

8. Finning KM, Martin PG, Soothill PW, Avent ND: Prediction of fetal D status from maternal plasma: introduction of a new noninvasive fetal RHD genotyping service. Transfusion 2002, 42:1079-1085.

9. der Schoot V, Tax C, Robbert J, Rijnders J, de Hass M, Christiaens: Prenatal typing of RH \& Kell Blood group system antigens: the edge of a watershed. Transfus Med Rev 2003, 17:31-44.

10. Avent $\mathrm{N}: \mathrm{RhD}$ Genotyping from maternal plasma: guidelines and technical challenges. In Methods in Molecular Biology. Edited by Hahn S, Jackson L. Totowa NJ: Humana Press; 2008:185-201.

11. Pregnant Women with Red Cell Antibodies: Scottish National Clinical Guidance; 2013. www.scotblood.co.uk/about-us/publications.aspx.

12. National Comparative Audit of Blood Transfusion. http://www.uhbristol.nhs. uk/patients-and-visitors/your-hospitals/st-michaels-hospital/what-we-do/ fetal-medicine-unit/rhesus-negative-ffdna-pilot.

13. Clausen FB, Christiansen M, Steffensen $R$, Jørgensen $S$, Nielsen $C$, Jakobsen MA, Madsen RD, Jensen K, Krog GR, Rieneck k, Sprogøe U, Homburg KM, Grunnet N, Dziegiel MH: Report of the first nationally implemented clinical routine screening for fetal RHD in D- pregnant women to ascertain the requirement for antenatal RhD prophylaxis. Transfusion 2011, 52(4):752-758.

14. de Haas M, van der Ploeg C, Scheffer PG, Verlinden DA, Hirshberg H, Abbink F, van der Schoot CE: A nationwide fetal RHD screening programme for targeted antenatal and postnatal anti-D. International Society of Blood Transfusion, ISBT Science Series 2012, 7:164-167.

15. Kent J, Farrell AM: Risky bodies in the plasma bioeconomy: a feminist analysis. In Body \& Society. in press.

16. Finlay, the Honourable Mr Justice T: Report of the Tribunal of Inquiry into The Blood Transfusion Service Board. Dublin: Stationery Office; 1997.

17. Schreier E, Hohne M, Kunkel U, Berg T, Hopf U: Hepatitis GBV-C sequences in patients infected with HCV, contaminated Anti-D immunoglobulin and among i.v. drug users in Germany. J Hepatol 1996, 25:385-389.

18. RCOG; 2011:8. op cit see note 6 above.

19. Bolton-Maggs, et al: op cit see note 5 above; 2013. http://www.shotuk.org/ home.

20. Department of Health: Better Blood Transfusion Safe and Appropriate Use of Blood HSC 2007/001. Department of Health; 2007.

21. Szczepura A, Osipenko L, Freeman K: A new fetal RhD genotyping test: costs and benefits of mass testing to target antenatal anti-D prophylaxis in England and Wales. BMC Pregnancy Childbirth 2011, 11:5.

22. Van der Schoot C, Ait Soussan A, Koelewijn J, Bonsel L, Paget-Christiaens L, de Haas M: Non Invasive antenatal RHD typing. Transfus Clin Biol 2006, 13:53-57.

23. Farrell AM: The Politics of Blood. Ethics, Innovation and the Regulation of Risk. Cambridge: CambridgeUniversity Press; 2012.

24. Rhesus negative ffDNA pilot. See http://hospital.blood.co.uk/safe_use/ clinical_audit/national_comparative (last accessed 17th February 2014).

doi:10.1186/1471-2393-14-87

Cite this article as: Kent et al:: Routine administration of Anti-D: the ethical case for offering pregnant women fetal $R H D$ genotyping and a review of policy and practice. BMC Pregnancy and Childbirth 2014 14:87.

\section{Submit your next manuscript to BioMed Central and take full advantage of:}

- Convenient online submission

- Thorough peer review

- No space constraints or color figure charges

- Immediate publication on acceptance

- Inclusion in PubMed, CAS, Scopus and Google Scholar

- Research which is freely available for redistribution 